\title{
Predictive value of graft patency and major adverse cardiac and cerebrovascular events (MACCEs) in coronary artery bypass grafting (CABG) based on Fourier transform (FFT)
}

\author{
Yanxiong Jia ${ }^{1,2}$, Hongyi $\mathrm{Xu}^{3}$, Pixiong $\mathrm{Su}^{2}$, Jie $\mathrm{Gao}^{2}$, Song $\mathrm{Gu}^{2}$, Yan $\mathrm{Liu}^{2}$, Xiangguang $\mathrm{An}^{2}$, Jun $\operatorname{Yan}^{2}$, \\ Xitao Zhang ${ }^{2}$ \\ ${ }^{1}$ Capital Medical University, Beijing, China; ${ }^{2}$ Department of Cardiovascular Surgery, Beijing Chao-yang Hospital, Capital Medical University, \\ Beijing, China; ${ }^{3}$ Beijing Institute of Electronic System Engineering, Beijing, China \\ Contributions: (I) Conception and design: Y Jia, H Xu; (II) Administrative support: Y Liu, P Su; (III) Provision of study materials or patients: Y Jia, J \\ Gao, S Gu, X An, J Yan, X Zhang, P Su; (IV) Collection and assembly of data: Y Jia; (V) Data analysis and interpretation: Y Jia, H Xu, J Gao; (VI) \\ Manuscript writing: All authors; (VII) Final approval of manuscript: All authors. \\ Correspondence to: Pixiong Su, MD. Department of Cardiovascular Surgery, Beijing Chao-Yang Hospital, 8 Gong Ti South Road, Chaoyang District, \\ Beijing 100020, China. Email: supixiong1130@163.com.
}

Background: Transit time flow measurement (TTFM) is widely used in coronary artery bypass grafting (CABG); however, its predictive value is unclear. We aimed to identify new factors to evaluate graft quality using fast Fourier transform (FFT).

Methods: Intraoperative and postoperative 2-year follow-up data of 114 patients undergoing CABG from January 2017 to December 2018 were collected. The TTFM waveform was transformed by FFT. Mean graft flow (MGF), pulse index, the amplitude of the main wave in FFT $\left(\mathrm{H}_{0}\right)$, the amplitude of the first harmonic $\left(\mathrm{H}_{1}\right), \mathrm{H}_{0} / \mathrm{H}_{1}$, and the frequency of the first harmonic $(\mathrm{P})$ were analyzed as predictors using logistic regression and receiver operating characteristic (ROC) curves.

Results: The overall graft patency rate was $80.3 \%$, and the incidence of major adverse cardiac and cerebrovascular events (MACCEs) was 14.9\%. The results demonstrate that compared with the graft failure group, MGF, $\mathrm{H}_{0}$, and $\mathrm{H}_{1}$ were higher, but $\mathrm{H}_{1}$ and $\mathrm{P}$ were lower in the patent group. With univariate and multivariate logistic regression analyses, the decrease in $\mathrm{H}_{0}$ and $\mathrm{H}_{1}$ and the increase in $\mathrm{P}$ were independent risk factors for graft failure, while the decrease in MGF and the increase in $\mathrm{H}_{0} / \mathrm{H}_{1}$ were only statistically significant with a univariate analysis. In the cardiovascular events group, the increase in $\mathrm{P}$ was an independent risk factor. With a ROC curve analysis, $\mathrm{MGF}, \mathrm{H}_{0}, \mathrm{H}_{1}, \mathrm{H}_{0} / \mathrm{H}_{1}$, and $\mathrm{P}$ predicted graft failure, while only $\mathrm{P}$ predicted cardiovascular events. None of the indicators showed predictive value for MACCEs.

Conclusions: TTFM waveforms after FFT can be used to evaluate graft quality and cardiovascular events, but have no predictive value for MACCEs.

Keywords: Coronary artery bypass; waveform analysis; fast Fourier transform (FFT); graft patency rate; major adverse cardiac and cerebrovascular events (MACCEs)

Submitted Jan 27, 2021. Accepted for publication Mar 14, 2021.

doi: $10.21037 /$ jtd-21-178

View this article at: http://dx.doi.org/10.21037/jtd-21-178

\section{Introduction}

Coronary artery bypass grafting (CABG) plays a vital role in treating coronary heart disease (1-3). The long-term prognosis of patients who have undergone surgery is the focal point of cardiac surgeons. We regularly use the graft patency rate and major adverse cardiac and cerebrovascular events (MACCEs) to evaluate CABG quality. Transit time flow measurement (TTFM) is a method used to evaluate anastomosis quality $(4,5)$. As it requires very few hardware 


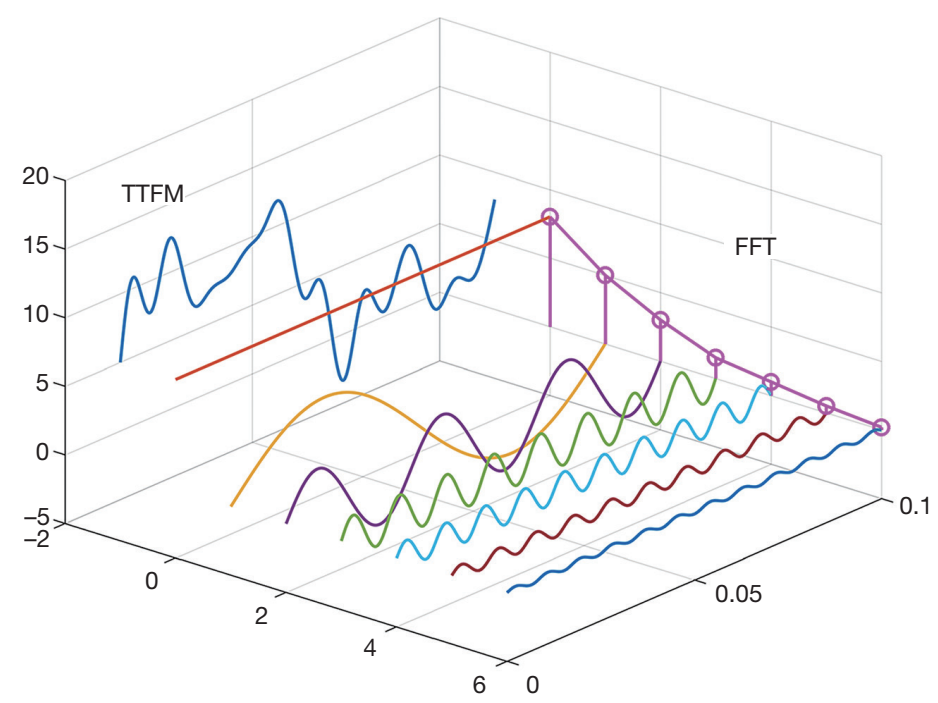

Figure 1 The principle of the fast Fourier transform. TTFM, Transit time flow measurement; FFT, fast Fourier transform.

facilities and little personal ability, it is convenient for intraoperative application. Guidelines (2) recommend a mean graft flow (MGF) of $>20 \mathrm{~mL} / \mathrm{h}$ and a pulse index (PI) of $<5$ as good indicators for evaluating graft anastomosis. Amin et al. (6) proposed that TTFM is an accurate indicator of graft flow in CABG. Di Giammarco et al. (7) found that the MGF rate, the PI, and systolic reverse flow (SRF) predict graft failure.

However, while many studies have confirmed the validity of TTFM, some doubts remain. For example, Thuijs et al. (8) conducted a meta-analysis that showed that only $25 \%$ of problem grafts recognized by TTFM actually underwent revascularization. Desai et al. (9) found that TTFM had only $25 \%$ sensitivity and $98 \%$ specificity for grafts with $>50 \%$ stenosis or occlusion. Singh et al. (10) found no significant difference in graft patency rate between TTFM and non-TTFM groups. Quin et al. (11) found that the association between TTFM use and clinical outcomes is uncertain.

Some studies have used methods, such as the analysis of TTFM waveforms, to improve the predictive value of TTFM. Takami et al. (5) introduced a method to transform TTFM waveforms using fast Fourier transform (FFT). They found that FFT waveforms had a good predictive value of graft patency. The greatest value of FFT is that it quantifies TTFM waveforms. The shape of blood flow waveforms differs in the time domain, but FFT can transform these waveforms into the frequency domain. As waveforms can be represented as the number of wave peaks with different frequencies in the frequency domain, they are easy to analyze (Figure 1). In Takami's (5) study, only $\mathrm{F}_{0} / \mathrm{H}_{1}$ (the ratio of the first 2 harmonics) was used as a predictor for graft failure, but many other FFT waveform parameters may also have predictive value. In this study, we sought to explore the predictive value of these factors for graft prognosis and to verify whether FFT can feasibly be used to evaluate graft quality.

We present the following article in accordance with the STROBE reporting checklist (available at http://dx.doi. org/10.21037/jtd-21-178).

\section{Methods}

\section{Study population}

A total of 114 patients who underwent CABG at Beijing Chao-Yang Hospital from January 2017 to December 2018 were enrolled in this study and followed up with for 2 years. The study was conducted in accordance with the Declaration of Helsinki (as revised in 2013). The study was approved by local research ethics board of Chaoyang Hospital (No. 2018-k-308) and individual consent for this retrospective analysis was waived. Notably, 6 patients did not wish to complete the follow-up examinations; thus, there was a follow-up loss rate of $5 \%$. Patients were included in this study if they underwent a left internal mammary artery (LIMA) or a saphenous vein graft (SVG) surgery, and were excluded if they underwent a concomitant valvular or other surgery, or those with hemodynamic instability, or those undergoing emergency operations. 
Of the 114 patients, 85 were male, and 29 were female. Patients had an average age of $61.82 \pm 8.53$ years. The average follow-up time was $24.89 \pm 6.91$ months, and the average graft number was $2.83 \pm 0.69$. Of the patients, 65 were smokers, 46 had diabetes mellitus, 74 had hypertension, 81 had hyperlipidemia, 2 had chronic renal insufficiency, 5 had peripheral vascular disease, 13 had previous cerebrovascular accidents, 30 had a previous myocardial infarction and 19 had undergone previous percutaneous coronary intervention.

\section{Surgical technique}

The same team of surgeons performed all surgeries. Each target vessel for CABG had more than $70 \%$ stenosis, which was confirmed by coronary angiography. All the patients provided written informed consent before surgery. All patients underwent elective CABG. The LIMA was obtained directly, and the great saphenous vein was obtained endoscopically. The LIMA was anastomosed to the left anterior descending (LAD) branch. The distal great SVG was anastomosed to the non-LAD artery or to the LAD artery when necessary, and the proximal SVG was anastomosed to the ascending aorta. TTFM was measured after anastomosis, and the MGF rate and the PI were obtained. Measurements were taken when patients had stable circulation, and the average arterial pressure was kept close to the physiological level. An appropriate TTFM probe was selected to fit the graft without squeezing. Papaverine was used when the LIMA was measured. The patients were heparinized during collection and were re-tested after protamine neutralization. The MATrix LABoratory (MATLAB, 2017a) was used to perform the FFT processing of the TTFM waveforms, obtain FFT image, and measure the amplitude of the main wave $\left(\mathrm{H}_{0}\right)$, the amplitude of the first harmonic $\left(\mathrm{H}_{1}\right)$, the frequency of the first harmonic $(\mathrm{P})$, and $\mathrm{H}_{0} / \mathrm{H}_{1}$.

\section{Follow-up}

In our study, the follow-up examination mainly focused on patients' symptoms, medication, and imaging. Patients' symptoms were monitored, and their computed tomography coronary angiography (CTCA) results were obtained up to 2 years after surgery, and MACCEs and graft lesions were recorded. 2 cardiac surgeons and 2 radiologists evaluated the CTCA results according to the Fitzgibbon criteria (12). Grafts with no stenosis or $<50 \%$ stenosis were defined as the patency group, and the rest were defined as the graft failure group. The predictive value of the above parameters for graft failure and MACCEs was also analyzed.

\section{Statistical analysis}

In the statistical analysis of graft failure, an individual graft was defined as a unit of analysis. For MACCEs, grafts were used as the unit to analyze FFT and TTFM parameters, while patients were used as the unit in other analyses. SPSS 26.0 was used to perform t-tests, non-parametric tests, binary logistic regression analysis, and receiver operating characteristic (ROC) curve analysis. A $\mathrm{P}$ value of $<0.05$ was considered statistically significant.

\section{Results}

Table 1 shows patients' baseline characteristics. A total of 320 grafts were used in 114 patients with a patency rate of $80.3 \%(257 / 320)$. The LIMA and SVG graft patency rates were $89.4 \%$ (101/113) and 75.4\% (156/207), respectively. Based on a standard that required an MGF $>20 \mathrm{~mL} / \mathrm{min}$ and a PI $<5$, only $7.18 \%(23 / 320)$ of the grafts and $16.67 \%$ (19/114) of the patients were required to undergo revision. All the LIMAs were anastomosed to the LAD artery. The SVG grafted patency rate to a different target coronary artery was not significantly different $\left(\chi^{2}=7.735, \mathrm{P}=0.357\right)$. There were 15 cases of repeat revascularization, 8 cases of myocardial infarction, 2 cases of stroke, and no cases of allcause death. A total of 17 MACCEs occurred, with a rate of $14.9 \%$.

Table 2 shows the TTFM and FFT data of different outcomes, and Figure 2 compares the patency and graft failure groups with FFT. When defining graft failure as a grouping variable, MGF $(\mathrm{P}=0.020), \mathrm{H}_{0}(\mathrm{P}<0.001)$, $\mathrm{H}_{1}(\mathrm{P}<0.001), \mathrm{H}_{0} / \mathrm{H}_{1}(\mathrm{P}<0.001)$, and $\mathrm{P}(\mathrm{P}<0.001)$ were significantly different between the patency and graft failure groups, but the PI $(\mathrm{P}=0.056)$ was not. When MACCEs was defined as a grouping variable, there was no significant difference in any of the two groups' parameters between the 2 groups.

The results of the binary logistic regression analysis of graft failure and MACCEs as dependent variables are shown in Table 3. Univariate and multivariate regression models were built. In relation to the univariate regression analysis, a decrease in MGF [odds ratio (OR) $0.98,95 \%$ confidence interval (CI): 0.96-1.00, $\mathrm{P}=0.021], \mathrm{H}_{0}(\mathrm{OR} 0.92,95 \% \mathrm{CI}$ : $0.90-0.95, \mathrm{P}<0.001), \mathrm{H}_{1}(\mathrm{OR} 0.45,95 \%$ CI: $0.36-0.56$, 
Table 1 baseline characteristics

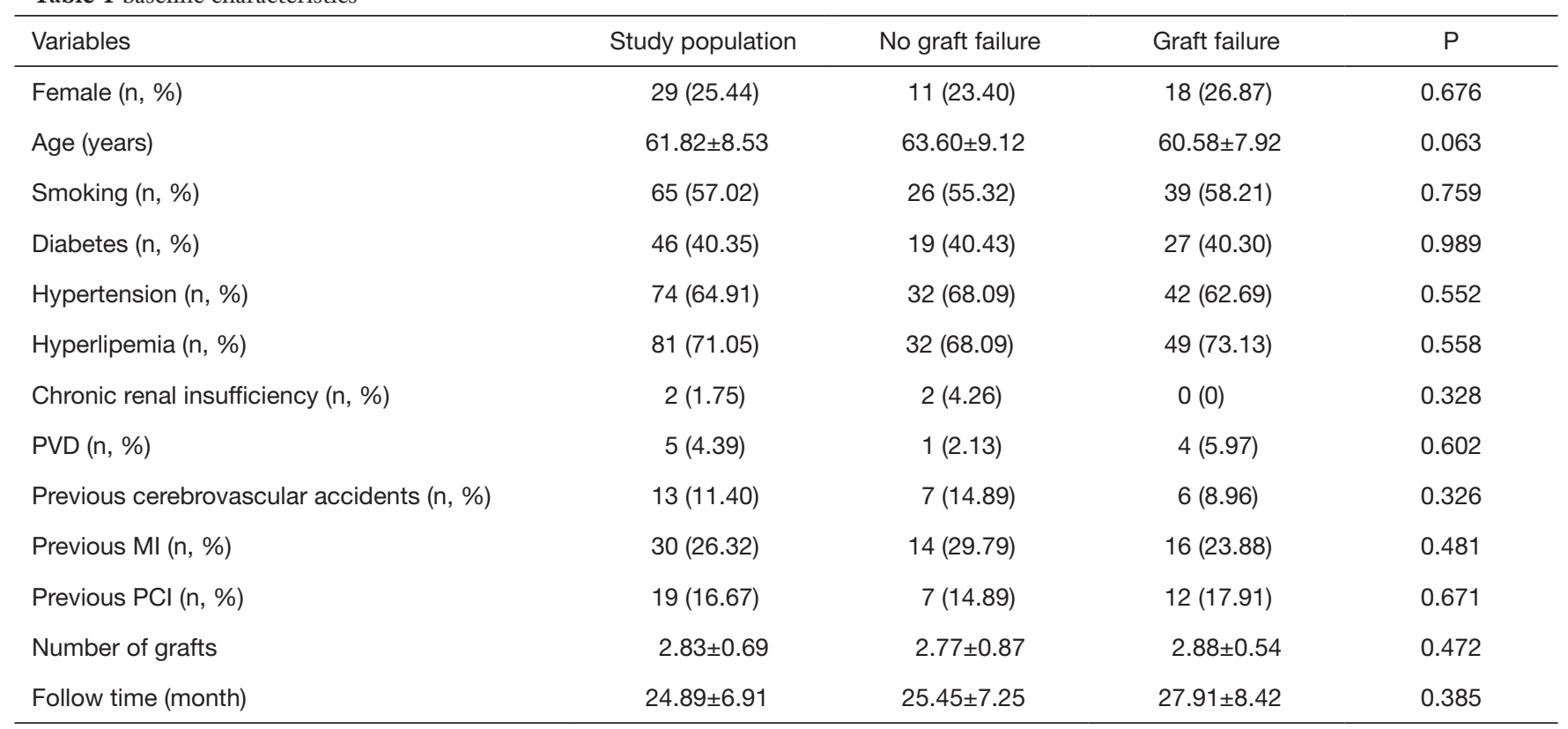

*, continuous variables with normal distribution are presented as mean \pm SD unless otherwise noted. PVD, peripheral vascular disease; MI, myocardial infarction; $\mathrm{PCl}$, percutaneous coronary intervention

Table 2 TTFM and FFT data of graft failure and MACCEs

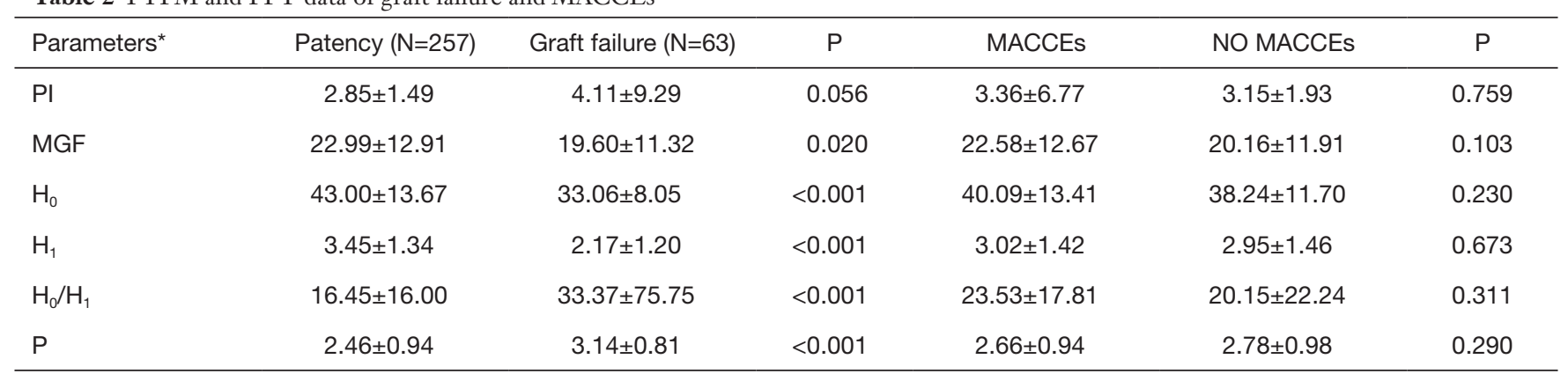

*, continuous variables with normal distribution are presented as mean \pm SD unless otherwise noted. PI, pulse index; MGF, mean graft flow; $\mathrm{H}_{0}$, the amplitude of the main wave; $\mathrm{H}_{1}$, the amplitude of the first harmonic; $\mathrm{P}$, the frequency of the first harmonic; MACCEs, major adverse cardiac and cerebrovascular events.

$\mathrm{P}<0.001)$, and an increase in $\mathrm{H}_{0} / \mathrm{H}_{1}(\mathrm{OR} 1.02,95 \%$ CI: 1.01-1.03, $\mathrm{P}<0.001)$ and $\mathrm{P}(\mathrm{OR} 2.43,95 \% \mathrm{CI}: 1.78-3.33$, $\mathrm{P}<0.001)$ were identified as independent risk factors affecting graft failure, but the PI was not. In relation to the multivariate regression analysis, a decrease in $\mathrm{H}_{0}(\mathrm{OR} 0.92$, 95\% CI: $0.89-0.95, \mathrm{P}<0.001)$ and $\mathrm{H}_{1}(\mathrm{OR} 0.43,95 \% \mathrm{CI}$ : $0.32-0.58, \mathrm{P}<0.001)$ and an increase in $\mathrm{P}(\mathrm{OR} 2.28,95 \%$ CI: 1.62-3.20, $\mathrm{P}<0.001$ ) were identified as independent risk factors. These factors were not risk factors for MACCEs. Table 4 sets out the multivariate binary logistic regression analysis results for the clinical factors of graft failure and MACCEs. The postoperative clopidogrel was an independent risk factor for graft failure (OR 2.43, 95\% CI: 1.07-5.51, $\mathrm{P}=0.033)$. The proportion of graft failure (OR 1.03 , 95\% CI: $1.01-1.05, \mathrm{P}=0.002$ ) was an independent risk factor for MACCEs.

To explore the predictive value of these indicators for cardiovascular events, we performed a logistic regression and ROC curve analyses in which repeat revascularization and myocardial infarction were the dependent variables. In relation to the logistic regression, only an increase in $\mathrm{P}$ was an independent risk factor for repeat revascularization 


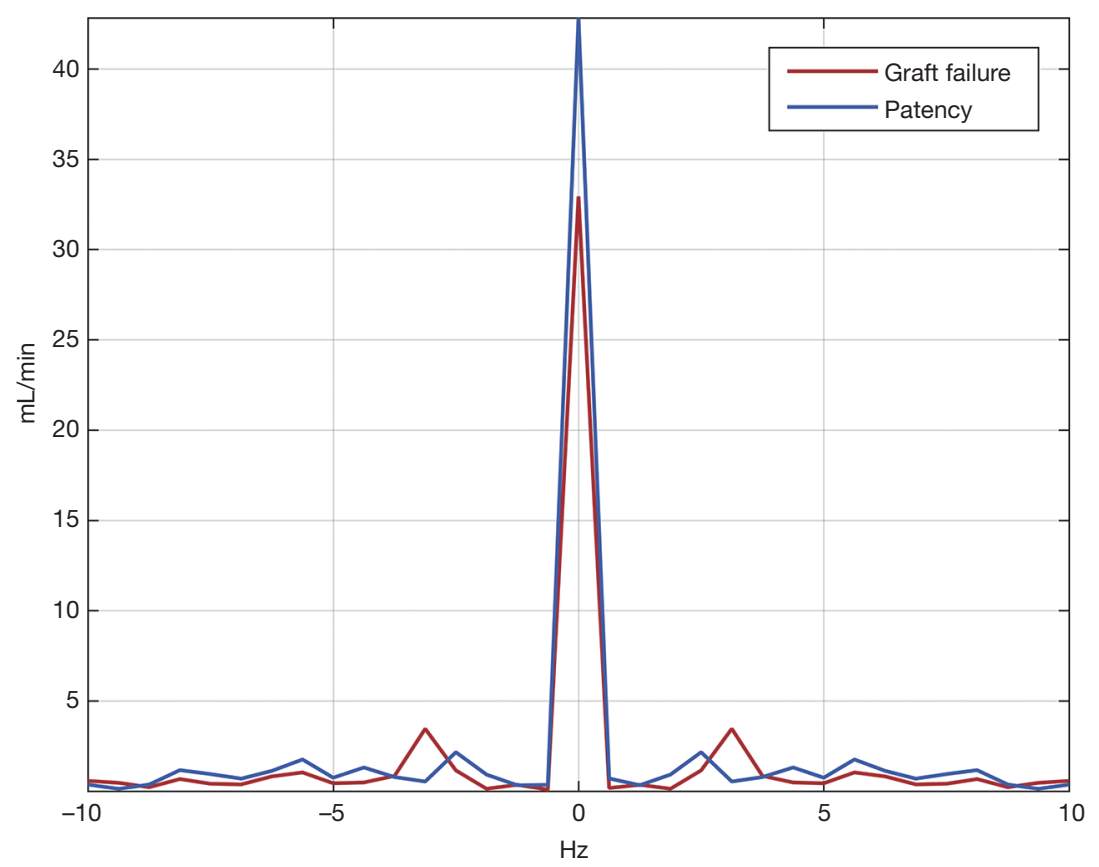

Figure 2 The comparison between the patency and graft failure groups with FFT. The figure shows the FFT curve of the graft failure group (red line) and the patency group (blue line). FFT, fast Fourier transform.

(univariate: OR 1.66, 95\% CI: $1.16-2.39, \mathrm{P}=0.006$; multivariate: OR 1.64, 95\% CI: $1.13-2.36, \mathrm{P}=0.008)$ and myocardial infarction (univariate: OR 1.90, 95\% CI: $1.21-$ 2.97, $\mathrm{P}=0.005$; multivariate: $\mathrm{OR} 1.86,95 \% \mathrm{CI}: 1.18-2.93$, $\mathrm{P}=0.008)$.

Table 5 and Figure 3 show the results of the ROC curve analysis. The cut-off values for predicting graft failure were as follows: MGF, $>23.90 \mathrm{~mL} / \mathrm{min}(\mathrm{P}=0.026)$, $\mathrm{H}_{0},>39.31 \mathrm{~mL} / \mathrm{min}(\mathrm{P}<0.001), \mathrm{H}_{1},>3.20 \mathrm{~mL} / \mathrm{min}(\mathrm{P}<0.001)$, $\mathrm{H}_{0} / \mathrm{H}_{1},<17.41(\mathrm{P}<0.001)$, and $\mathrm{P}<2.99 \mathrm{~Hz}(\mathrm{P}<0.001)$. However, the PI was not a significant predictor of graft failure $(\mathrm{P}=0.259)$. In the MACCEs group, none of the parameters had predictive value $(\mathrm{P}>0.050)$. In the repeat revascularization and myocardial infarction groups, only $\mathrm{P}$ had predictive value with cut-off values of $3.24 \mathrm{~Hz}(\mathrm{P}=0.008)$ and $3.10 \mathrm{~Hz}(\mathrm{P}=0.037)$, respectively.

\section{Discussion}

TTFM is an important method to assess intraoperative graft quality in CABG. The main indicators of TTFM include MGF, the PI, the diastolic filling index, and SRF. These parameters are calculated using a formula on the TTFM blood flow waveform to reflect blood flow characteristics in grafts. Among these parameters, MGF and the PI are the most important in a clinical setting. In a retrospective analysis of the ROOBY study, Quin et al. (13) found that the re-graft rate was significantly higher in the low MGF group $(<20 \mathrm{~mL} / \mathrm{min}$ ) than the high $\mathrm{MGF}$ group $(>20 \mathrm{~mL} / \mathrm{min}$ ). Lehnert et al. (14) conducted a 1-year follow-up study of grafts and found a significant correlation between MGF and graft failure. Concerning the PI, Jokinen et al. (15) and Di Giammarco et al. (16) reported that a PI of $>3$ could be used as a predictor of graft failure, while Tokuda et al. (17) reported that a PI of $>5$ could be used as a cut-off. In the present study, grafts in the patency group had a higher MGF rate $(\mathrm{P}=0.020)$ than those of the graft failure group, but the difference in the PI was not significant $(\mathrm{P}=0.056)$ between the two groups. The logistic regression and ROC curve analyses showed that the PI was also not related to graft failure. Indeed, the formula for PI shows that it is inversely proportional to MGF. Except for the MGF rate, the PI's factor is the difference between the maximum and minimum blood flow. High sharp waves and negative blood flow can increase this difference. These features are more alarming to surgeons than MGF. Quin et al. (13) also confirmed that the re-anastomosis rate increased with an increase in the PI. No significant difference in the PI was found between the two groups; however, the average PI in the patency group was lower than that of the graft failure 
Table 3 The results of the binary logistic regression analysis of graft failure and MACCEs

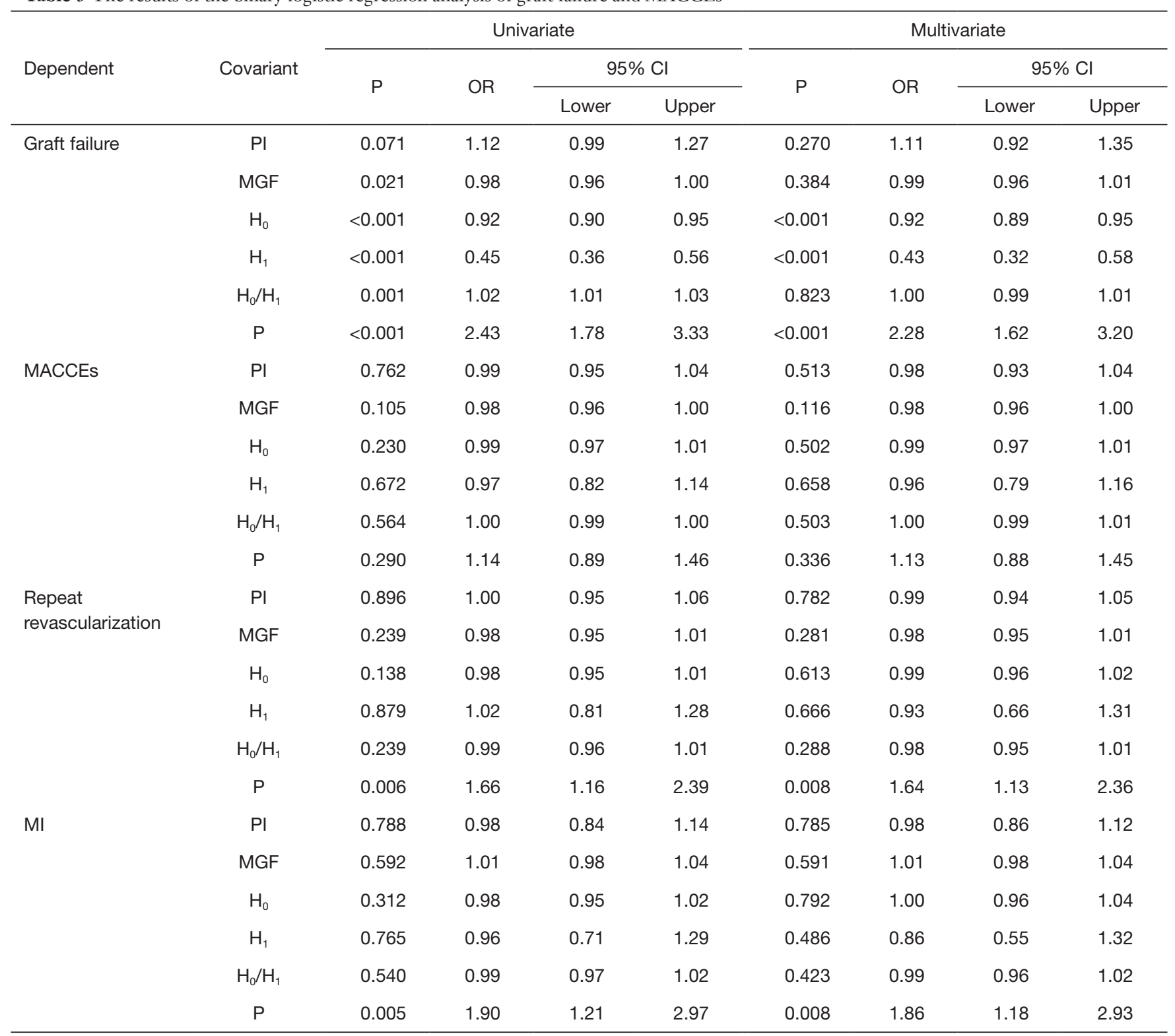

MACCEs, major adverse cardiac and cerebrovascular events; MI, myocardial infarction; OR, odds ratio; Cl, confidence interval. PI, pulse index; MGF, mean graft flow; $\mathrm{H}_{0}$, the amplitude of the main wave; $\mathrm{H}_{1}$, the amplitude of the first harmonic; $\mathrm{P}$, the frequency of the first harmonic.

group. Thus, we believe that a higher MGF rate predicts better graft quality, and while there was no significant difference, a lower PI tends to lead to a better prognosis.

In the present study, we used FFT as a transfer method for TTFM waveforms. Figure 1 shows that the time domain's blood flow waveform was transformed into the FFT waveform in the frequency domain. The waveform of FFT comprised the main crest $\left(\mathrm{H}_{0}\right)$ and many harmonics
$\left(\mathrm{H}_{1}-\mathrm{H}_{\mathrm{n}}\right)$. In our study, the main crest was equivalent to MGF, but this was a trend, not an equal number. The harmonics reflected the complexity of the TTFM waveform. For example, the sine wave has only 1 harmonic, and the more harmonics, the more complex the wave. The frequency of harmonics also reflected waveform complexity; the higher the frequency, the shorter the period of change, and the lesser the similarity between the waveform and the 
Table 4 The results of the binary logistic regression analysis for clinical factors

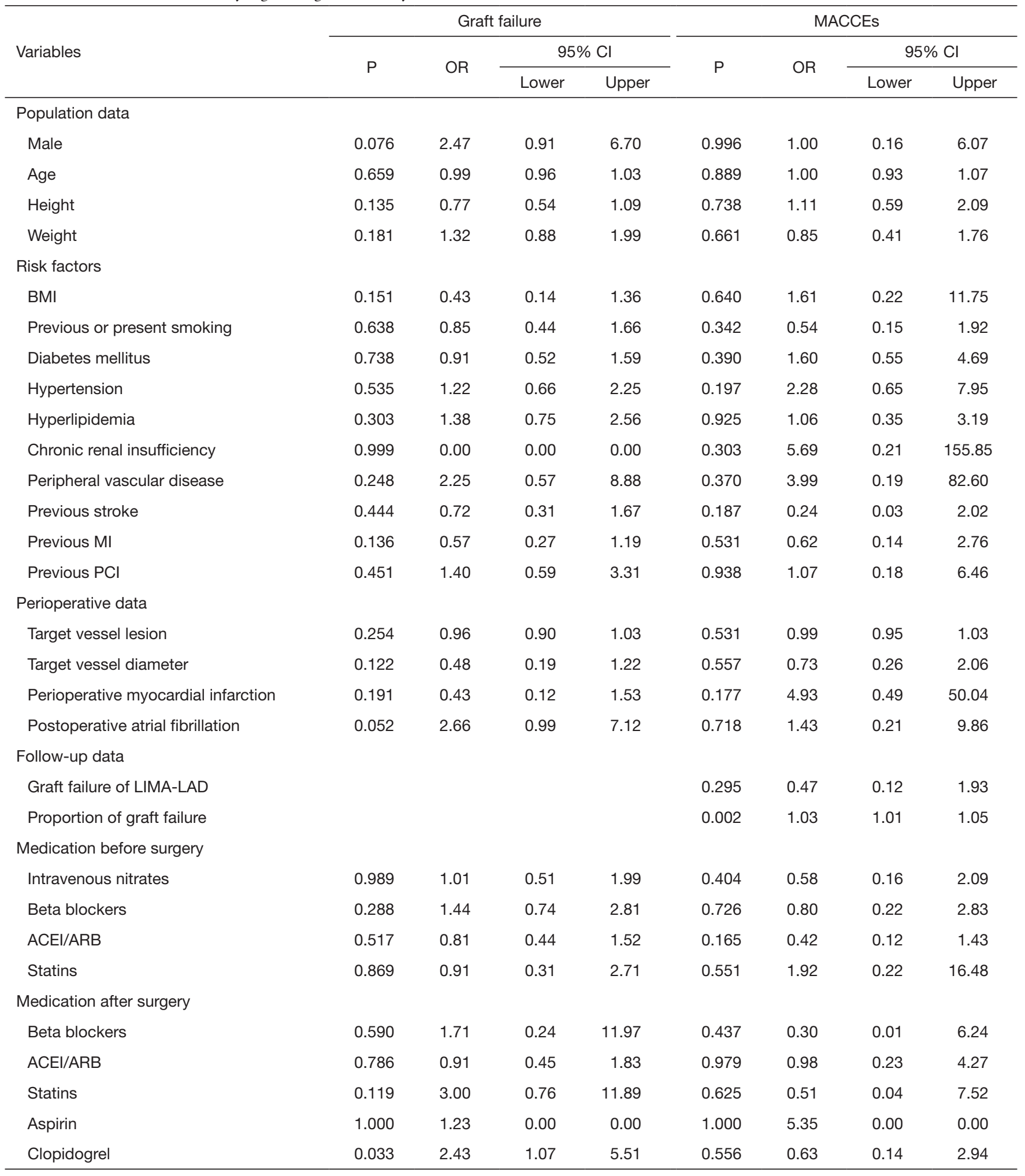

MACCEs, major adverse cardiac and cerebrovascular events; BMI, body mass index; MI, myocardial infarction; PCI, percutaneous coronary intervention; LIMA, left internal mammary artery; LAD, left anterior descending branch; ACEl, angiotensin-converting enzyme inhibitors; ARB, angiotensin receptor blockers; OR, odds ratio; Cl, confidence interval. 
Table 5 The results of the ROC curve analysis

\begin{tabular}{|c|c|c|c|c|c|c|}
\hline Test variable & State variable & AUC & SE & $\mathrm{P}$ & \multicolumn{2}{|c|}{$95 \% \mathrm{Cl}$} \\
\hline \multirow[t]{5}{*}{ Graft failure } & $\mathrm{PI}$ & 0.462 & 0.034 & 0.259 & 0.395 & 0.529 \\
\hline & MGF & 0.575 & 0.034 & 0.026 & 0.509 & 0.641 \\
\hline & $\mathrm{H}_{0}$ & 0.720 & 0.028 & $<0.001$ & 0.666 & 0.775 \\
\hline & $\mathrm{H}_{0} / \mathrm{H}_{1}$ & 0.625 & 0.033 & $<0.001$ & 0.561 & 0.690 \\
\hline & $\mathrm{P}$ & 0.707 & 0.029 & $<0.001$ & 0.650 & 0.763 \\
\hline \multirow[t]{4}{*}{ MACCE } & $\mathrm{PI}$ & 0.475 & 0.035 & 0.466 & 0.406 & 0.543 \\
\hline & MGF & 0.562 & 0.035 & 0.074 & 0.494 & 0.630 \\
\hline & $\mathrm{H}_{0} / \mathrm{H}_{1}$ & 0.500 & 0.035 & 0.994 & 0.431 & 0.568 \\
\hline & $\mathrm{P}$ & 0.474 & 0.034 & 0.444 & 0.406 & 0.541 \\
\hline \multirow[t]{6}{*}{ Repeat revascularization } & $\mathrm{PI}$ & 0.556 & 0.049 & 0.254 & 0.460 & 0.652 \\
\hline & MGF & 0.571 & 0.049 & 0.146 & 0.474 & 0.668 \\
\hline & $\mathrm{H}_{0}$ & 0.563 & 0.047 & 0.196 & 0.471 & 0.656 \\
\hline & $\mathrm{H}_{1}$ & 0.508 & 0.046 & 0.864 & 0.419 & 0.598 \\
\hline & $\mathrm{H}_{0} / \mathrm{H}_{1}$ & 0.450 & 0.048 & 0.302 & 0.356 & 0.543 \\
\hline & $\mathrm{P}$ & 0.630 & 0.048 & 0.008 & 0.537 & 0.724 \\
\hline MI & $\mathrm{P}$ & 0.631 & 0.062 & 0.037 & 0.509 & 0.752 \\
\hline
\end{tabular}

MACCEs, major adverse cardiac and cerebrovascular events; MI, myocardial infarction; AUC, area under the curve; SE, standard error; CI, confidence interval. PI, pulse index; MGF, mean graft flow; $\mathrm{H}_{0}$, the amplitude of the main wave; $\mathrm{H}_{1}$, the amplitude of the first harmonic; $\mathrm{P}$, the frequency of the first harmonic.

sine wave. As the description of waveform shape has strong subjectivity, there are few studies in this field. We used FFT to transform the shape of the waveform into data that could be analyzed, which was our initial aim.

According to our results, patent grafts tended to have higher $\mathrm{H}_{0}$ and $\mathrm{H}_{1}$ values and lower $\mathrm{P}$ values. As stated above, $\mathrm{H}_{0}$ reflected MGF, which is consistent with most studies that state that a higher MGF indicates a better graft quality. $\mathrm{H}_{1}$ and $\mathrm{P}$ reflected the characteristics of the first harmonic. We analyzed the first harmonic because it was the most obvious in the FFT waveform. The sum of harmonic amplitude values is a definite value; thus, a higher $\mathrm{H}_{1}$ equates to a lower amplitude for the other harmonics. High-frequency harmonics represent more complex TTFM waveforms, such as high sharp waves or tremor waves caused by vasospasm. Concerning amplitude, these harmonics are positively correlated with abnormal waveforms. Thus, in an ideal TTFM waveform, each harmonic 

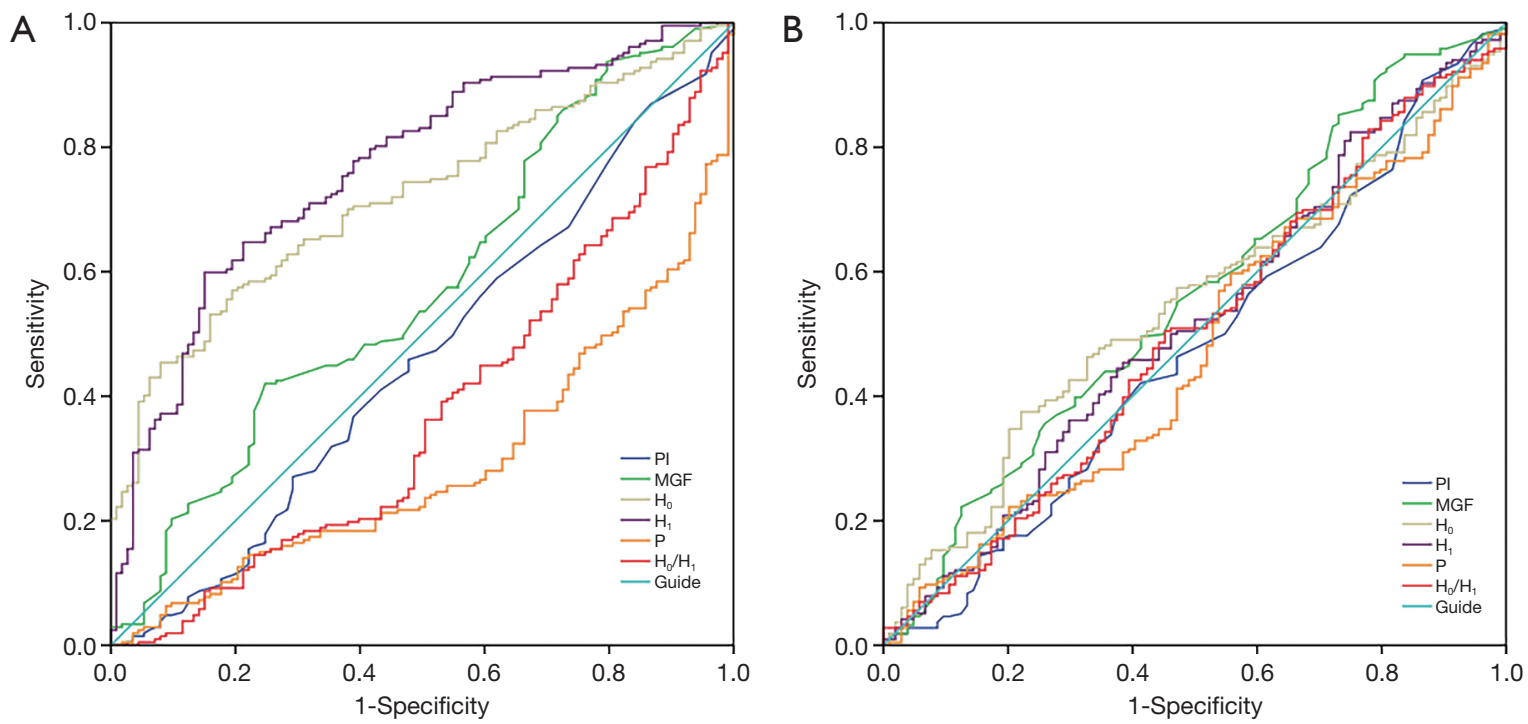

Figure 3 The ROC curve of outcomes after surgery. The ROC curve of graft failure (A) and $M A C C E s(B) . M G F, P I, H_{0}, H_{1}, H_{0} / H_{1}$, and $P$ are using as predictors for analysis. ROC, receiver operating characteristic; MACCEs, major adverse cardiac and cerebrovascular events; PI, pulse index; $\mathrm{MGF}$, mean graft flow; $\mathrm{H}_{0}$, the amplitude of the main wave; $\mathrm{H}_{1}$, the amplitude of the first harmonic; $\mathrm{P}$, the frequency of the first harmonic.

frequency and the amplitude beyond the first harmonic should be as low as possible. These characteristics are consistent with the results obtained in our research. $\mathrm{H}_{0} / \mathrm{H}_{1}$ had predictive value in graft evaluation; however, its accuracy was lower than that of other parameters, and thus its use is not recommended.

In the analysis of MACCEs, none of the indicators showed predictive value. A number of points should be noted. First, it might be because TTFM only reflects graft quality, while MACCEs cover a wider range (11). Second, while some patients had graft failure, no cardiovascular symptoms were observed due to long-term ischemic tolerance or collateral circulation. Third, incomplete revascularization in some patients led to cardiovascular symptoms in the short term after surgery. Finally, the sample size was small; thus, it is possible that the sample was unable to reflect this trend. When we considered cardiovascular events as a dependent variable, we found that the $\mathrm{P}$ was a statistically significant predictor of cardiovascular events. These results suggest that graft quality correlates with postoperative cardiovascular events. However, to predict MACCEs, a more comprehensive approach is needed.

The present study had relatively low graft patency rates, which the low revision rate might have caused. Additionally, we believe that patients with symptoms were more likely to participate in the follow-up examinations, and this bias led to a lower patency rate. Future research will find ways to eliminate any such bias to ensure more valuable data is gathered. We also found consistent with the guideline recommendations; the postoperative clopidogrel was an independent risk factor for graft failure. Thus, it is our view that after CABG, all patients should be routinely treated with dual antiplatelet therapy, except those with antiplatelet contraindications.

The present study had several limitations. First, this study was performed at a single center with a relatively small cohort of patients. Thus, the level of evidence for the conclusion is low. Second, only the LIMA and the SVG were used. Future research should include more graft types. Third, our transform process was based on a MATLAB code that we wrote ourselves. We performed FFT on each TTFM waveform and manually acquired various data in this process. However, as a consequence, the results are not universal and are difficult to replicate. We hope that TTFM instrument manufacturers will realize the value of FFT in the future.

\section{Conclusions}

TTFM waveforms that undergo FFT can be used to evaluate graft quality and cardiovascular events. $\mathrm{H}_{0}, \mathrm{H}_{1}$, and 
$\mathrm{P}$ are predictive parameters for graft failure, but they have no predictive value for MACCEs. MGF is also a predictor of graft failure, while the PI has no predictive value. We believe that the combination of TTFM measurement and FFT will improve the evaluation accuracy of graft quality in future clinical applications.

\section{Acknowledgments}

We would like to thank the Medical Records and Statistics Room, Beijing Chao-yang Hospital, which provided hospital discharge data.

Funding: None.

\section{Footnote}

Reporting Checklist: The authors have completed the STROBE reporting checklist. Available at http://dx.doi. org/10.21037/jtd-21-178

Data Sharing Statement: Available at http://dx.doi. org/10.21037/jtd-21-178

Conflicts of Interest: All authors have completed the ICMJE uniform disclosure form (available at http://dx.doi. org/10.21037/jtd-21-178). The authors have no conflicts of interest to declare.

Ethical Statement: The authors are accountable for all aspects of the work in ensuring that questions related to the accuracy or integrity of any part of the work are appropriately investigated and resolved. The study was conducted in accordance with the Declaration of Helsinki (as revised in 2013). The study was approved by local research ethics board of Chaoyang Hospital (No. 2018-k-308) and individual consent for this retrospective analysis was waived.

Open Access Statement: This is an Open Access article distributed in accordance with the Creative Commons Attribution-NonCommercial-NoDerivs 4.0 International License (CC BY-NC-ND 4.0), which permits the noncommercial replication and distribution of the article with the strict proviso that no changes or edits are made and the original work is properly cited (including links to both the formal publication through the relevant DOI and the license). See: https://creativecommons.org/licenses/by-nc-nd/4.0/.

\section{References}

1. Thuijs D, Kappetein AP, Serruys PW, et al. Percutaneous coronary intervention versus coronary artery bypass grafting in patients with three-vessel or left main coronary artery disease: 10-year follow-up of the multicentre randomised controlled SYNTAX trial. Lancet 2019;394:1325-34.

2. Neumann F, Sousa-Uva M, Ahlsson A, et al. 2018 ESC/ EACTS Guidelines on myocardial revascularization. Eur Heart J 2019;40:87-165.

3. Cummings IG, Lucchese G, Garg S, et al. Ten-year improved survival in patients with multi-vessel coronary disease and poor left ventricular function following surgery: A retrospective cohort study. Int J Surg 2020;76:146-52.

4. Kieser TM, Taggart DP. The use of intraoperative graft assessment in guiding graft revision. Ann Cardiothorac Surg 2018;7:652-62.

5. Takami $Y$, Ina H. Relation of Intraoperative Flow Measurement With Postoperative Quantitative Angiographic Assessment of Coronary Artery Bypass Grafting. Ann Thorac Surg 2001;4:1270-4.

6. Amin S, Werner RS, Madsen PL, et al. Intraoperative Bypass Graft Flow Measurement With Transit Time Flowmetry: A Clinical Assessment. Ann Thorac Surg 2018;106:532-8.

7. Di Giammarco G, Pano M, Cirmeni S, et al. Predictive value of intraoperative transit-time flow measurement for short-term graft patency in coronary surgery. J Thorac Cardiovasc Surg 2006;132:468-74.

8. Thuijs DJFM, Bekker MWA, Taggart DP, et al. Improving coronary artery bypass grafting: a systematic review and meta-analysis on the impact of adopting transit-time flow measurement. Eur J Cardiothorac Surg 2019;56:654-63.

9. Desai ND, Miwa S, Kodama D, et al. A randomized comparison of intraoperative indocyanine green angiography and transit-time flow measurement to detect technical errors in coronary bypass grafts. J Thorac Cardiovasc Surg 2006;132:585-94.

10. Singh SK, Desai ND, Chikazawa G, et al. The Graft Imaging to Improve Patency (GRIIP) clinical trial results. J Thorac Cardiovasc Surg 2010;139:294-301, 301.e1.

11. Quin JA, Noubani M, Rove JY, et al. Coronary Artery Bypass Grafting Transit-Time Flow Measurement: Graft Patency and Clinical Outcomes. Ann Thorac Surg 2020. doi: 10.1016/j.athoracsur.2020.12.011. 
12. Fitzgibbon GM, Kafka HP, Leach AJ, et al. Coronary bypass graft fate and patient outcome: angiographic followup of 5,065 grafts related to survival and reoperation in 1,388 patients during 25 years. J Am Coll Cardiol 1996;28:616-26.

13. Quin J, Lucke J, Hattler B, et al. Surgeon Judgment and Utility of Transit Time Flow Probes in Coronary Artery Bypass Grafting Surgery. JAMA Surg 2014;149:1182.

14. Lehnert P, Moller CH, Damgaard S, et al. Transit-time flow measurement as a predictor of coronary bypass graft failure at one year angiographic follow-up. J Card Surg 2015;30:47-52.

15. Jokinen JJ, Werkkala K, Vainikka T, et al. Clinical value

Cite this article as: Jia Y, Xu H, Su P, Gao J, Gu S, Liu Y, An X, Yan J, Zhang X. Predictive value of graft patency and major adverse cardiac and cerebrovascular events (MACCEs) in coronary artery bypass grafting (CABG) based on Fourier transform (FFT). J Thorac Dis 2021;13(5):2705-2715. doi: $10.21037 /$ jtd-21-178 of intra-operative transit-time flow measurement for coronary artery bypass grafting: a prospective angiographycontrolled study. Eur J Cardiothorac Surg 2011;39:918-23.

16. Di Giammarco G, Canosa C, Foschi M, et al. Intraoperative graft verification in coronary surgery: increased diagnostic accuracy adding high-resolution epicardial ultrasonography to transit-time flow measurement. Eur J Cardiothorac Surg 2014;45:e41-e45.

17. Tokuda Y, Song M, Ueda Y, et al. Predicting Early Coronary Artery Bypass Graft Failure by Intraoperative Transit Time Flow Measurement. Ann Thorac Surg 2007;84:1928-33. 